\title{
Electroencephalographic studies in hereditary myopathy
}

\author{
DAVID D. BARWICK, J. W. OSSELTON, AND JOHN N. WALTON \\ From the Regional Neurological Centre and the Department of Psychological Medicine, Newcastle General \\ Hospital, Newcastle upon Tyne
}

Recent reports by a number of authors have suggested that electroencephalographic (E.E.G.) abnormalities are often found in patients with progressive muscular dystrophy. Winfield, Britt, and Raskind (1958) reported the finding of nine abnormal records in 12 children with muscular dystrophy subjected to E.E.G. study. The abnormalities consisted of the pattern designated by Gibbs and Gibbs (1952) as 14 and 6 per second positive spikes.

Wayne and Browne-Mayers (1959), in a study of 57 dystrophic patients of whom 21 were adults and 36 were children, found a total incidence of definite abnormality in 17 cases. The changes consisted of generalized abnormalities of various kinds and there was no correlation between the severity of the E.E.G. abnormalities and the clinical severity of the dystrophy.

Ascione, Matano, and Serra (1959) found E.E.G. changes in five boys with muscular dystrophy, all in the same sib-ship. The changes consisted of generalized abnormalities which developed during photic stimulation and hyperventilation.

Perlstein, Gibbs, Gibbs, and Stein (1960) reported a large series of examinations on patients suffering from what the authors referred to as various forms of myopathy. Unfortunately, not all of their 101 patients were in fact cases of muscular dystrophy. Included in this series were 22 cases of amyotonia congenita; this is a clinical diagnosis, the syndrome commonly embracing primary neuropathic disorders such as infantile spinal musuclar atrophy (Werdnig-Hoffman disease), as well as various myopathic disorders. A further nine patients are reported to have had 'probable myopathies' but no further details are given. Of the 70 remaining patients, eight were suffering from facioscapulohumeral dystrophy and 62 were children with pseudohypertrophic dystrophy. In these two groups the incidence of abnormalities in the E.E.G. was $45 \%$ ( 28 patients) in the children and $37 \%$ (three patients) in the group with facioscapulohumeral dystrophy. The most commonly observed abnormalities were 14 and 6 per second positive spikes and these were seen particularly in the children.

Di Gruttola, Fanuele, and Berni Canani (1961) studied 12 patients, all children with pseudohypertrophic muscular dystrophy. They found E.E.G. abnormalities in 10 patients, the changes consisting of slow dominant rhythms and generalized excesses of slow activity; they did not observe any 14 or 6 per second positive spikes.

\section{MATERIAL AND METHODS}

We decided to investigate a series of patients suffering from muscular dystrophy of various types. Those studied fell into the following four clinical groups, according to the criteria suggested by Walton and Nattrass (1954): 1 Duchenne type of progressive muscular dystrophy in young boys; 2 limb-girdle dystrophy; 3 facioscapulohumeral dystrophy; and, 4 dystrophia myotonica.

The study was carried out on a total of 65 patients and 48 controls. Table I shows the number of subjects in each diagnostic and control group and their average ages. Eighteen of the patients with Duchenne dystrophy, all of whom were males, were under the age of 20 years. These were matched with respect to sex and approximate age with 18 controls.

TABLE I

PATIENTS AND CONTROLS STUDIED IN THIS SURVEY Type of Dystrophy Number of Cases Average Age in Years

\begin{tabular}{lll}
\hline Duchenne & 20 & $13 \cdot 8$ \\
Limb-girdle & 14 & $39 \cdot 7$ \\
Facioscapulohumeral & 13 & $31 \cdot 5$ \\
Dystrophia myotonica & 18 & $45 \cdot 2$ \\
Adult controls (over 20) & 30 & 36.9 \\
Juvenile controls (under 20) & 18 & $11 \cdot 4$
\end{tabular}

None of the patients had any history of epilepsy or clinical evidence of primary neurological disease.

The adult controls were volunteers (mainly staff) from the Department of Psychological Medicine and were free from any history of neurological or psychiatric disorder. The juvenile controls were referred from the Department of Child Heath; they also were free from any neurological or psychiatric disorder and had been admitted for medical or surgical investigation; none was febrile at the time of 
the E.E.G. recording. The recordings were obtained on standard 8-channel A.E.I. equipment with the aid of chlorided silver pad electrodes. Electrode placements were according to the international $10-20$ system. Several bipolar montages and a unipolar montage employing two reference electrodes were used. The great majority of the recordings were taken with the subjects recumbent, but a few patients who were distressed by this position were allowed to sit up. No provocative techniques were used. Fourteen of the patients with Duchenne dystrophy and 12 of the juvenile controls had a second recording following the administration of 500 to $1,000 \mathrm{mg}$. glutethamide (doriden). Those who subsequently fell asleep were gently awakened while the recording was in progress using the double reference unipolar montage with the intention of facilitating the appearance of 14 and 6 per second positive sharp waves.

The records from all the patients and controls over the age of 20 years were sent in random order, identified only by age and sex, but not by diagnosis, to each of us in turn for interpretation and were classified into one of the following categories:-
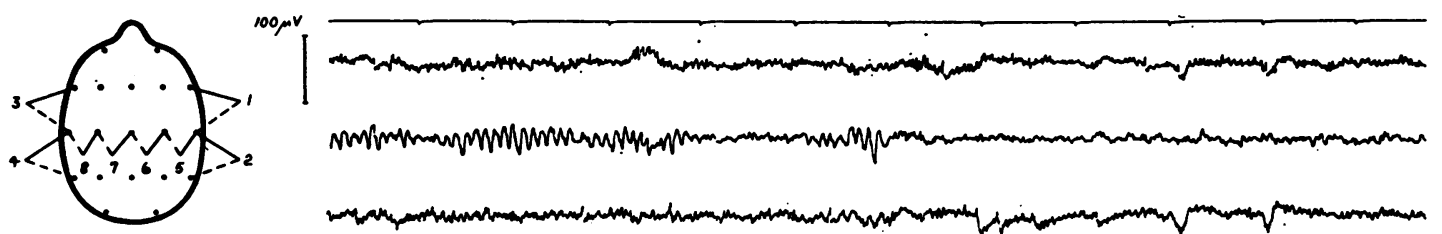

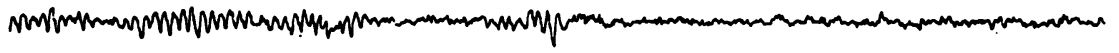
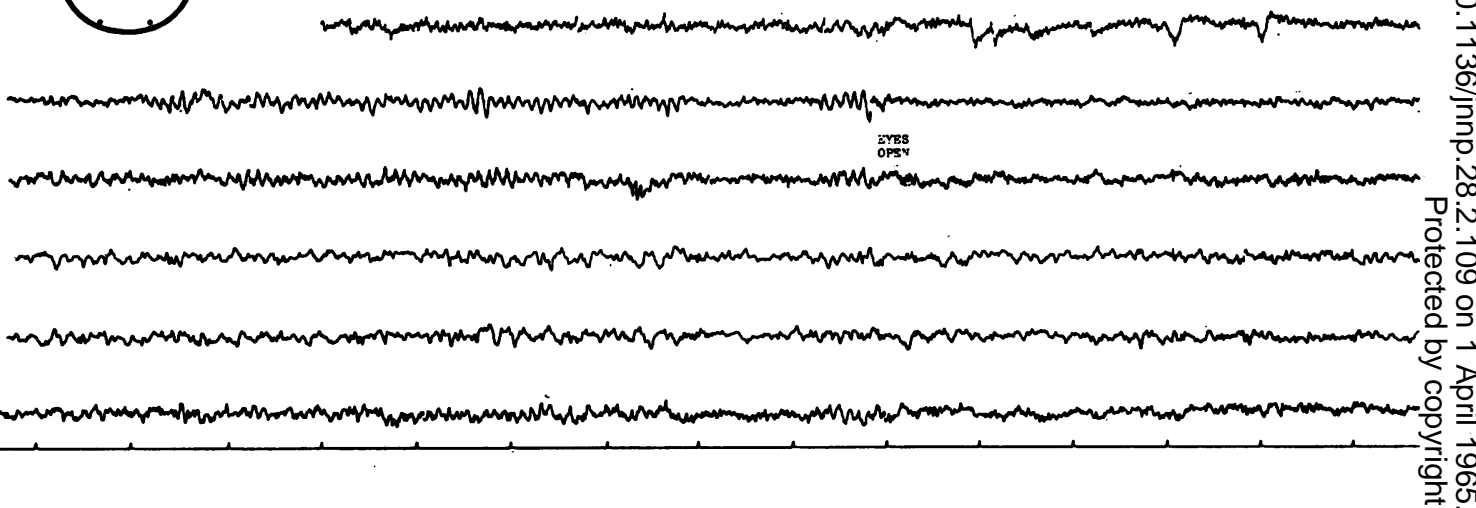

FIG. 1. Type 1 abnormality: the record shows a moderate excess of theta about the vertex. Control aged 20. (All T.C.s 0.3 sec.; paper speed $3 \mathrm{~cm} . / \mathrm{sec}$.).

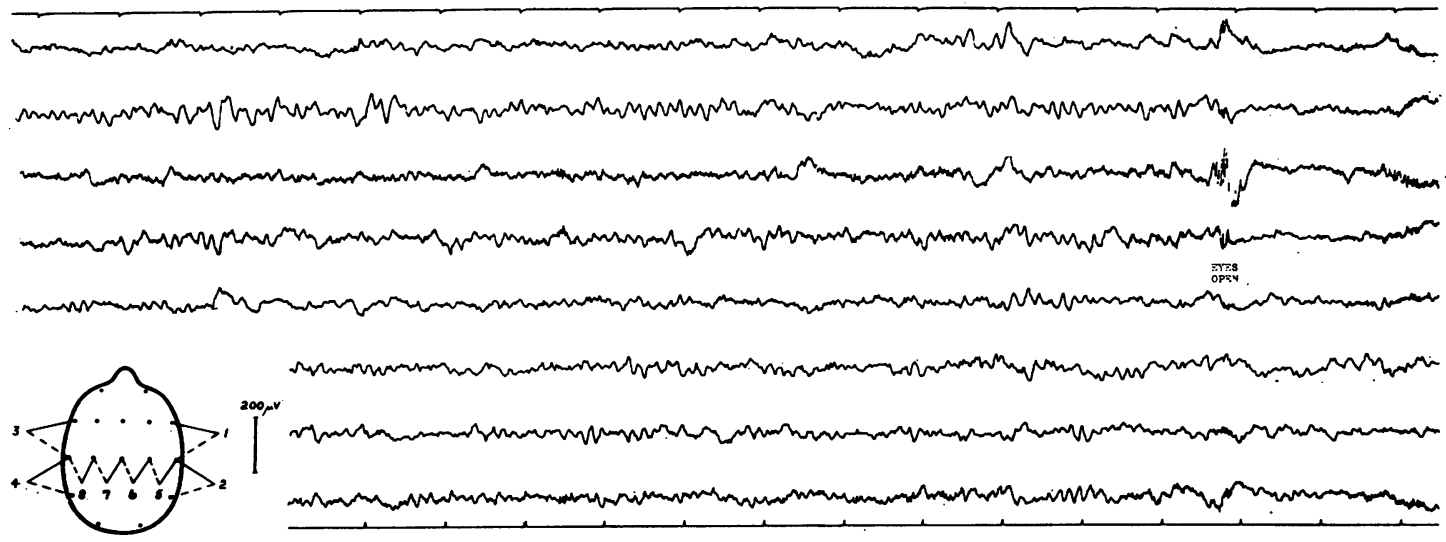

FIG. 2. Type 2 abnormality: the record shows a marked excess of theta and delta activity, particularly in the posterior temporal regions. Patient aged 8, diagnosis Duchenne dystrophy. (All T.C.s $0 \cdot 3$ sec.; paper speed $3 \mathrm{~cm} . / \mathrm{sec}$.). 
o Within normal limits

1 Moderate excess of theta activity posteriorly or about the vertex (Fig. 1)

2 Marked excess of theta or delta activity or both

(Fig. 2) or a dominant rhythm at less than $8 \mathrm{c} / \mathrm{s}$ (Fig. 3)

3 Focal sharp wave discharges (Fig. 4)

Records in the latter three categories were regarded as abnormal and were designated types 1,2 , and 3 . When the authors' initial ratings of a particular record did not agree, it was subsequently discussed jointly until agreement was reached. There was initial disagreement in less than $10 \%$ of records; this was usually slight and a final agreed classification was invariably reached without difficulty.

The records from the patients and controls under the age of 20 years were grouped in pairs, each comprising the records from a patient and a control of the same age, and were presented to two of us (D.D.B. and J.W.O.) in turn. Because of the less clearly defined criteria of normality in this age group, these records were first placed individually into one of three categories, namely, normal, borderline, and abnormal. Secondly, when the records in a matched pair had both been allocated to the same category, an opinion was expressed, whenever possible, as to which was the more 'abnormal' or less
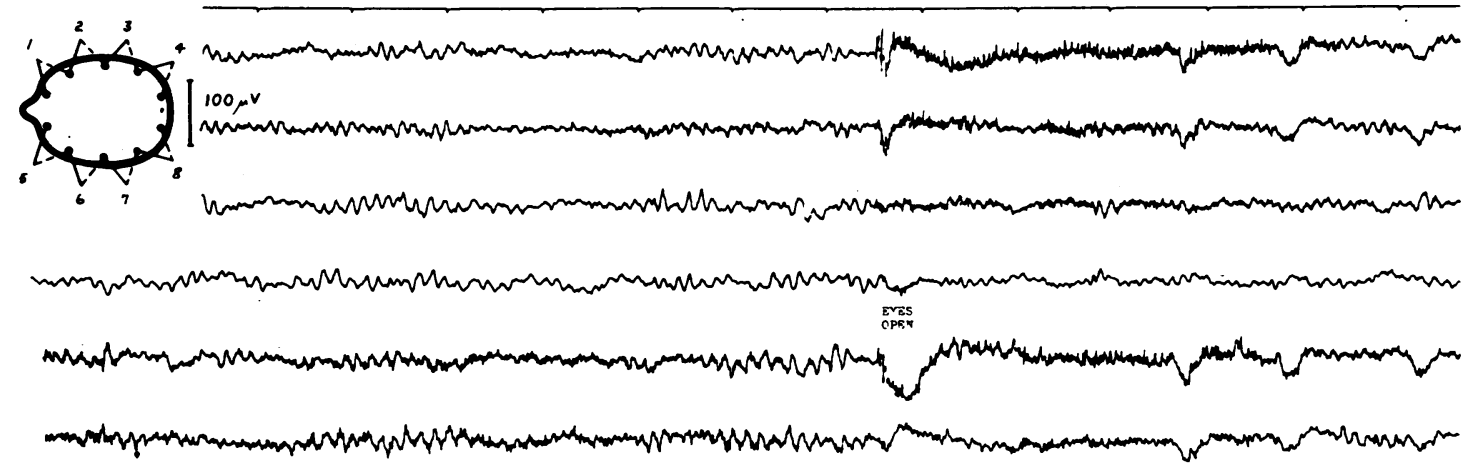

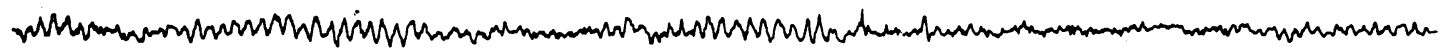

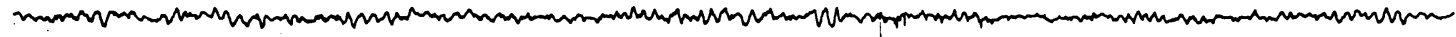

FIG. 3. Type 2 abnormality: the dominant posterior activity is a responsive rhythm at about 6 cycles per second. Patient aged 58, diagnosis dystrophia myotonica. (All T.C.s $0.3 \mathrm{sec} . ;$ paper speed $3 \mathrm{~cm} . / \mathrm{sec}$.).
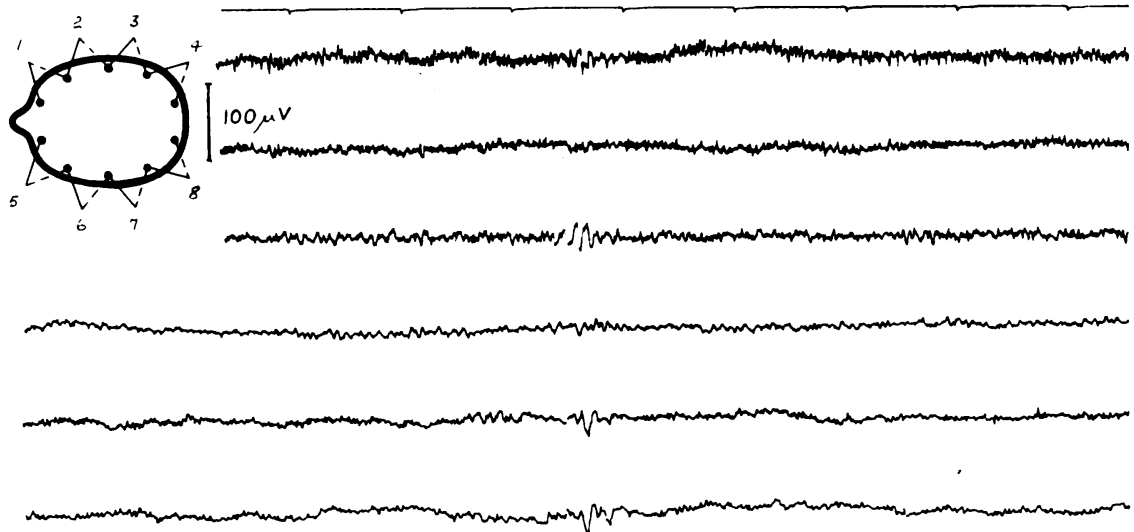

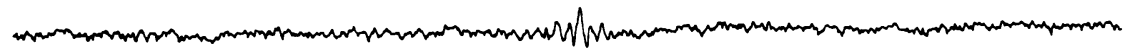

FIG. 4. Type 3 abnormality; there is a focal sharp wave discharge in the left mid-temporal region. Patient aged 35, diagnosis limb-girdle dystrophy. (All T.C.s 0.3 sec.; paper speed $3 \mathrm{~cm} . / \mathrm{sec}$.).

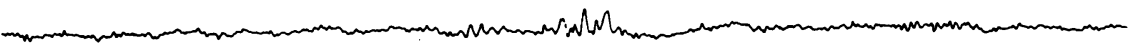


'normal'. Thus, in a pair of records, both of which had been classified as within normal limits for age, that which showed the higher proportion of theta to alpha activity, for instance, would be classed as less 'normal' than the other. In this way it was hoped that a more subtle difference between the records of the patients and those of the controls might be revealed.

\section{RESULTS}

The occurrence of abnormal records in the four groups of patients with different varieties of muscular dystrophy and in the group of adult controls is shown in Table II. Taking all the dystrophies to-

\section{TABLE II}

INCIDENCE OF NORMAL AND ABNORMAL RECORDS IN DYSTROPHIC AND ADULT CONTROL GROUPS

\begin{tabular}{lcrr} 
Type of Dystrophy & $\begin{array}{c}\text { Number of } \\
\text { Cases }\end{array}$ & Normal & Abnormal \\
\hline Duchenne & 20 & $17(85 \%)$ & $3(15 \%)$ \\
Limb-girdle & 14 & $12(86 \%)$ & $2(14 \%)$ \\
Facioscapulohumeral & 13 & $10(77 \%)$ & $3(23 \%)$ \\
Dystrophia myotonica & 18 & $7(39 \%)$ & $11(61 \%)$ \\
Adult controls & 30 & $24(80 \%)$ & $6(20 \%)$
\end{tabular}

gether, the average incidence of abnormal records is $29 \%$ which is not significantly different, with this number of cases, from the incidence of $20 \%$ in the adult controls. However, comparing the incidence of $61 \%$ abnormal records in the patients with dystrophia myotonica with the incidence of $20 \%$ in the adult controls, reveals a difference which is significant at the $2 \%$ level of confidence: $\chi^{2}=5.9$ with Yates' correction. The incidence of different types of abnormality in this group is shown in Table III.

\section{TABLE III}

INCIDENCE OF DIFFERENT TYPES OF RECORD IN CASES OF DYSTROPHIA MYOTONICA

\begin{tabular}{lcc} 
Type of Record & No. & Incidence (\%) \\
\hline Normal & 7 & 39 \\
Type 1 & 3 & 17 \\
Type 2 & 6 & 33 \\
Type 3 & 2 & 11
\end{tabular}

When the results obtained independently by two of us (D.D.B. and J.W.O.) in assessing the records from the 18 patients under the age of 20 years with Duchenne dystrophy and their matched controls were compared, considerable discrepancies were noted. These were mainly due to the fact that one of us adopted more stringent criteria of normality than the other. It was therefore decided to re-assess jointly those pairs of records in which a major difference of opinion had occurred. The joint results thus obtained are shown in Table IV.
TABLE IV

INCIDENCE OF NORMAL, BORDERLINE, AND ABNORMAL RECORDS IN PATIENTS WITH DUCHENNE TYPE DYSTROPHY AND IN MATCHED CONTROLS

\begin{tabular}{lrr} 
Type of Record & Patients & Controls \\
\hline Normal & $13(72 \%)$ & $10(55 \%)$ \\
Borderline & $4(22 \%)$ & $5(28 \%)$ \\
Abnormal & $1(6 \%)$ & $3(17 \%)$
\end{tabular}

When the same records were examined in pairs matched with respect to age, it was agreed that the patient's record was the more 'abnormal' in three pairs, that the control's record was the more 'abnormal' in 10 pairs and that there were five pairs in which the records were substantially the same. Notwithstanding the differences of opinion which initially existed in the assessment of these records, there is certainly no evidence to suggest that E.E.G. abnormalities are consistently associated with the Duchenne type of muscular dystrophy.

Fourteen of the patients under the age of 20 years returned for a further recording after sedation with glutethamide (doriden). Seven slept and seven did not, though all of the latter became drowsy. What $\infty$ abnormalities there were in the initial parts of these ? records before the patient fell asleep became les $\vec{B}$ evident or disappeared altogether when they did so Appreciable stretches of these records were taken with a montage that was thought likely to enhance the appearance of 14 and 6 per second positive sharp waves, namely one in which the active electrodes (anterior, mid and posterior temporal and occipital on one side were referred to a common under-eaF of electrode on the other side. The patients, if asleep, were gently awakened while recording was in progress with this montage, but in no case were any clear 14 and 6 per second discharges seen.

\section{DISCUSSION}

In the communication of Winfield et al. (1958) the clinical criteria for the diagnosis of muscular dystrophy were first pseudohypertrophy, and secondly, the onset of the disease in childhood. According to Walton and Nattrass (1954) it is likely that most of these patients would be cases of Duchenne type dystrophy, but both the limb-girdle and the facioscapulohumeral dystrophies may begin in childhood and can sometimes be accompanied by pseudohypertrophy.

Wayne and Browne-Mayers (1959) simply grouped their cases into adult and childhood forms of dystrophy, the age division being 16 years. Again, according to Walton and Nattrass, it is likely that both groups contained patients with the Duchenne type of dystrophy and the adult group would probably be a very miscellaneous one. 
Ascione et al. (1959) studied five cases, all brothers, and almost certainly all suffering from the Duchenne type of dystrophy. However, the E.E.G. findings were incidental to clinical, electromyographic and therapeutic investigations.

In the large series reported by Perlstein et al. (1960) some of the difficulties in assessing the results have already been mentioned. They did differentiate between pseudohypertrophic dystrophy and facioscapulohumeral dystrophy but we do not consider that their clinical criteria in making the differentiation were adequate as described. The main abnormalities found by these authors were 14 and 6 per second positive sharp waves and these were found mainly in the children. All their patients had E.E.G.s taken in the sleeping as well as the waking state and a common reference system of recording was used. Both of these factors were likely to increase the prominence of these discharges. No control records were taken and interpretation, although apparently carried out by independent observers, was not done in a 'blind' manner, as in our series.

In our cases we have not seen 14 and 6 per second positive sharp waves in patients or controls, either in bipolar waking records or in common reference sedation records, the latter being taken in the hope of finding such changes.

Turning to the work of Di Gruttola et al. (1961), we encounter the same difficulty of exact classification, as their cases were simply described as 12 patients with 'childhood muscular dystrophy'. It is, however, worth noting that they did not encounter 14 and 6 per second positive sharp waves.

Our own study was controlled and each observer assessed all the records independently in a 'blind' manner. We may conclude that we have failed to demonstrate E.E.G. abnormalities in patients suffering from muscular dystrophy of the limb girdle and facioscapulohumeral types. These are two relatively benign, slowly-progressive and restricted forms of dystrophy. Nor did we find any significant incidence of abnormality in children suffering from the Duchenne type of dystrophy, when compared with the records of a group of normal children of similar age and sex.

In the present study, there was a significant incidence of abnormality in the E.E.G.s of patients with dystrophia myotonica. This disease is characterized by a variety of manifestations; in addition to the dystrophic process affecting distal muscles, patients also show myotonia, cataract, frontal baldness, testicular atrophy, and mental dullness (Walton and Nattrass, 1954). A recent study by Refsum (1961) revealed progressive enlargement of the cerebral ventricles in a patient with this condition when air encephalography was repeated over a period of four years. Furthermore, respiratory insufficiency with chronic alveolar hypoventilation is common in such cases (Kilburn, Eagan, Sieker, and Heyman, 1959). Thus there is considerable evidence of associated cerebral and metabolic abnormalities in patients with dystrophia myotonica and the finding of abnormal E.E.G.s in a high proportion of such cases is not therefore surprising. Electroencephalographic changes in a series of 10 individuals with dystrophia myotonica have been reported by Savoldi (1959); two records were markedly abnormal, showing diffuse slow activity, and in eight slow dominant rhythms were present. Very recently a series of 26 patients also suffering from myotonic dystrophy has been studied by Friedlander and Bittenbender (1964). The E.E.G.s were abnormal in five cases, showing a slow dominant posterior rhythm, and the patients also showed a statistically significant incidence of records with alpha activity in the lower normal range when compared with a group of controls. We now intend to investigate the effect upon the E.E.G. of various metabolic changes in greater detail. We would, however, conclude that we have been unable to demonstrate that the 'pure' muscular dystrophies (Walton, 1964) of the Duchenne, limb-girdle, and facioscapulohumeral forms are accompanied by any significant abnormality in the electroencephalograph.

\section{SUMMARY}

Electroencephalograph recordings have been carried out in 65 patients with various forms of muscular dystrophy (20 Duchenne type, 14 limb-girdle, 13 facioscapulohumeral, 18 dystrophia myotonica) and have been compared in a 'blind' manner by three independent observers with records obtained from 48 control individuals of comparable age and sex.

No consistent abnormalities were found in records from cases of 'pure' muscular dystrophy (Duchenne, limb-girdle, and facioscapulohumeral) but a highly significant proportion $(61 \%)$ of cases of dystrophia myotonica gave abnormal records. The significance of these findings is discussed.

We wish to express our thanks to Mrs. Norma Little, who took the majority of the E.E.G. recordings. This work was aided by research grants from the Muscular Dystrophy Associations of America, Inc., the Muscular Dystrophy Association of Canada, and the Muscular Dystrophy Group of Great Britain.

\section{REFERENCES}

Ascione, A., Matano, F., and Serra, C. (1959). Aspetti elettroencefalografici, elettromiografici, enzimoplasmatici e prospettive terapeutiche nella distrofia muscolare progressiva. Rif. med., 73, 789-795. 
Di Gruttola, G., Fanuele, G., and Berni Canani, M. (1961). Indagini elettroencefalografiche in bambini con distrofia muscolare progressiva. Boll. Soc. ital. Biol. sper., 37, 847-849.

Friedlander, W. J., and Bittenbender, J. B. (1964). EEG findings in myotonia dystrophica. Electroenceph. clin. Neurophysiol., 17, 564-566.

Gibbs, F. A., and Gibbs, E. L. (1952). Atlas of Electroencephalography, vol. 2, Epilepsy. Addison-Wesley, Cambridge, Mass.

Kilburn, K. H., Eagan, J. T., Sieker, H. O., and Heyman, A. (1959). Cardiopulmonary insufficiency in myotonic and progressive muscular dystrophy. New Engl. J. Med., 261, 1089-1096.

Perlstein, M. A., Gibbs, F. A., Gibbs, E. L., and Stein, M. D. (1960).

- Electroencephalogram and myopathy. J. Amer. med. Ass., 173, 1329-1333.
Refsum, S. (1961). Luftencefalografi ved dystrophia myotonica. Nord. Med., 65, 822-823.

Savoldi, F. (1959). EEG patterns in Steinert's disease. Electroenceph. clin. Neurophysiol., 11, 386.

Walton, J. N. (1964). Muscular dystrophy: some recent advances in knowledge. Brit. med. J., 1, 1271-1274, 1344-1348.

- - and Nattrass, F. J. (1954). On the classification, natural history and treatment of the myopathies. Brain, 77, 169-231.

Wayne, H. L., and Browne-Mayers, A. N. (1959) Clinical and EEG observations in patients with progressive muscular dystrophy. Dis. nerv. Syst., 20, 288-291.

Winfield, D. L., Britt, L. P., and Raskind, R. (1958). EEG findings in pseudohypertrophic muscular dystrophy. Sth. med. J. (Bgham, Ala.), 51, 1251-1259. 